\title{
Controls on the standing crop of benthic foraminifera at an oceanic scale
}

\author{
Daniel O. B. Jones ${ }^{1, *}$, John W. Murray ${ }^{2}$ \\ ${ }^{1}$ National Oceanography Centre, University of Southampton Waterfront Campus, European Way, Southampton SO14 3ZH, UK \\ ${ }^{2}$ Ocean and Earth Science, National Oceanography Centre, University of Southampton, European Way, \\ Southampton SO14 3ZH, UK
}

\begin{abstract}
At present, there is very little basin-scale information on patterns of standing crop in marine organisms or their structuring forces. Understanding modern patterns and controls on foraminifera is particularly critical because of their abundance and importance in benthic systems, as well as their role as palaeoceanographic proxies. Here, we examine for the first time basin-scale patterns and predictors of benthic foraminiferal standing crop from the shelf to abyssal deep sea in the Atlantic Ocean and adjacent seas using a large database of 967 quantitative samples. Spatial regression analyses reveal that the flux of particulate organic matter is a major control on standing crop size across all depths investigated, with increasing food supply increasing foraminiferal standing crops. Other factors also play a role. Dissolved oxygen is significant at slope depths and negatively related to standing crop. Temperature and possibly salinity are locally significant factors in the abyss. This study demonstrates that productivity is important in describing foraminiferal standing crop at the basin scale, supporting its use as a palaeoceanographic proxy, but also demonstrates that other environmental variables are also likely important in controlling the standing crop and should be considered in reconstruction of Earth's past marine environment.
\end{abstract}

KEY WORDS: Atlantic Ocean and adjacent seas - Meiofauna $\cdot$ Infauna $\cdot$ Density $\cdot$ Benthicpelagic coupling $\cdot$ Palaeoceanography

\section{INTRODUCTION}

Foraminifera are protists that may have shells and therefore have a long fossil record. Most ecological studies have been carried out to aid the interpretation of fossil assemblages, but benthic foraminifera play an important role in both modern and ancient ecosystems (Gooday 2003). Modern benthic foraminifera are generalists (Van der Zwaan et al. 1999), although different species have different environmental requirements, and are abundant in modern environments ranging from supratidal marshes to hadal trenches (see Murray 2006 for a summary of distributions and ecology).

${ }^{*}$ Corresponding author: dj1@noc.ac.uk
They are crucial for marine ecosystem functioning (Gooday et al. 1992). They play a role in dentitrifcation under anoxic conditions and this function enables benthic foraminifera to continue to calcify their tests (Nardelli et al. 2014). Some species respond rapidly to the input of phytodetritus in both shallow-water and deep-sea systems and appear to be important for processing organic matter and transfer of energy to higher trophic levels (Gooday 1988, 2003). Benthic foraminifera are important in benthic carbon remineralisation and cycling of other nutrients (Gooday et al. 1992). They are also important in monitoring pollution in modern seas and marginal marine environments (Alve et al.

() The authors 2017. Open Access under Creative Commons by Attribution Licence. Use, distribution and reproduction are unrestricted. Authors and original publication must be credited. 
2016) and down-core studies can be used to reconstruct ecological conditions prior to the onset of pollution to aid remediation (Alve et al. 2009). Furthermore, foraminifera are widely used in palaeoceanographic reconstructions, especially using material from deep-sea drilling (Gooday \& Jorissen 2012), and for reconstructing past environments in petroleum exploration (e.g. Jones 2009). Thoughtful and comprehensive reviews of palaeoceanographic proxies based on benthic foraminifera, discussing the history of interpretations of the controls on deep sea species-from water depth, to water masses, to localised lowoxygen, to organic flux - have been provided by Gooday (2003) and Jorissen et al. (2007 and references therein). The stable isotopic and trace element records of calcareous tests are invaluable for palaeoceanographic reconstructions (e.g. Katz et al. 2010). At present, oxygen and organic flux are the most recognised primary controls of foraminiferal distributions of species assemblages and standing crop.

Global climate change, ocean acidification and anthropogenic activities have the potential to alter the ecology and biogeography of populations inhabiting the world's seabeds, with the Atlantic being a key region of change (Jones et al. 2014). Empirical evidence from time-series studies and manipulative experiments indicates that such changes will have a significant impact on marine ecosystems and associated ecosystem functions (Smith et al. 2008). By understanding the relationships between key ecological variables, such as standing crop, and their biotic and abiotic drivers, we can begin to predict the responses of ecosystems to future change. These relationships are poorly described in marine ecosystems owing to the limited availability of robust data for many marine taxa, particularly in deeper waters (but see Tittensor et al. 2010). High-quality data for key taxa at a regional scale will greatly improve our understanding of macroecological patterns, both for the taxon in question and for the purpose of providing information for wider ecosystem assessments (e.g. Rex et al. 2006).

Ecological studies of benthic foraminifera carried out on a local scale normally reveal correlations between species abundance and some of the environmental variables. However, when assessed on a broader regional scale, these local correlations are not always confirmed. The aim of this study was to consider these ecological relationships for the deep sea and continental shelves at the scale of an ocean and to determine the main drivers.

\section{METHODS}

\section{Treatment of standing crop and environmental data}

This study is based on standing crop (density) data (Rose Bengal stained material) for the top $0-1 \mathrm{~cm}$ of sediment (sample volume $10 \mathrm{~cm}^{3}$ ). The staining method for distinguishing individuals considered to be alive at the time of collection was introduced in 1952 by Walton (Walton 1952) and has been widely used ever since. Data on the deep sea and continental shelves were obtained from as many literature studies as possible from the period 1952-2013 (Murray 2015). Therefore, the dataset is not an instantaneous snapshot but a synopsis of data gathered over 6 decades. This study focuses on the Atlantic Ocean and adjacent parts of the Arctic and Southern oceans, as well as the Mediterranean and Gulf of Mexico/Caribbean. For this analysis, data from the deep sea and continental

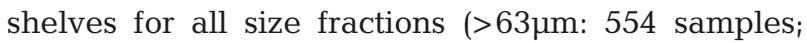
$>106 \mu \mathrm{m}$ : 14 samples; $>125 \mu \mathrm{m}$ : 351 samples; $>150 \mu \mathrm{m}$ : 49 samples) were combined (Tables S1 \& S2 in Supplement 2 at www.int-res.com/articles/suppl/m581 p071_supp2.xlsx). There were generally larger standing crops of foraminifera in the smaller size fraction samples (see Text S1 in Supplement 1 at www.int-res. com/articles/suppl/m581p071_supp1.pdf). The size fraction was incorporated into the statistical models as a covariate. In cases where the size fraction was not significant, it was removed in backward stepwise elimination (see 'Statistical analyses and modelling of data'). The significance value for removal was set high $(p=0.15)$, as trends were expected to reduce the likelihood of type I error. The potential influence of sieve-size-based differences is explored further in Text S1 in Supplement 1.

Potential drivers of standing crop patterns were chosen based on established hypotheses relating to temperature (seabed temperature), productivity (flux of particulate organic carbon [POC]), oxygen stress (dissolved oxygen [DO]), nutrient availability and salinity, which are known to affect standing crop in the marine environment (Tittensor et al. 2010), including that of foraminifera (Jorissen et al. 2007). Environmental variables were obtained from Internet-based resources as follows: temperature (Locarnini et al. 2013), salinity (Zweng et al. 2013), oxygen (Garcia et al. 2014a) and nutrient data (Garcia et al. 2014b) were obtained from World Ocean Atlas (using the deepest available depth band for each cell). Nutrient data, including phosphate, nitrate and silicate, were included to identify potential unexplained biochemical (e.g. marine production, respiration and 
oxidation of labile organic matter) and physical (e.g. water mass renewal and mixing) processes (Garcia et al. 2014b) not captured by the other datasets. Annual average POC flux data were obtained. POC flux was estimated as a function of satellite-derived net primary production and seasonal variation by Lutz et al. (2007). Data on the saturation state for calcite $\left(\Delta \mathrm{CO}_{3}{ }^{2-}\right.$ equivalent) available in global maps (Archer $1996 \mathrm{a}, \mathrm{b})$ allowed examination of the distribution of foraminifera relative to the lysocline. The lysocline is at 0 on this index, negative values indicate that the record is below the lysocline, positive is above. Data for all variables (temperature, salinity, oxygen, nutrients and POC flux) were extracted for each foraminiferal record and used as potential explanatory variables. Unfortunately, there are no detailed data compilations of sediment lithology or sea-floor currents at the scale necessary for this analysis, although both are known to influence foraminiferal assemblages not only on the shelf but also in the deep sea (e.g. Schönfeld 2002). Depth was not included in the models as an environmental factor as hydrostatic pressure would not be expected to exert as strong an influence as other highly correlated environmental controls, such as POC flux (e.g. Lutz et al. 2007; in our data: Spearman rank correlation between depth and POC flux: $\rho=-0.76, p<0.001$ ).

\section{Statistical analyses and modelling of data}

Spatial autocorrelation occurs when the values of variables sampled at nearby locations are not independent from each other (Dormann et al. 2007). When modelling the relationship between environmental predictors and response variables, spatial autocorrelation violates the assumptions of traditional statistical approaches (Tittensor et al. 2010). Spatial autocorrelation was determined from a variogram, which depicts the variance between pairs of points at increasing distances between points (Dormann et al. 2007). The variance between points for our data, as is typically the case, increases up to a certain distance and then levels off (the sill). Model fits, using the R function 'gstat', indicate that the sill starts at a range of $980 \mathrm{~km}$, suggesting spatial correlation exists up to a regional scale. This spatial autocorrelation results in deflated estimates of variance and corresponding impacts on inference, among other issues. As a result, variables were modelled and inferences drawn using both generalized linear models (GLMs) and multivariate spatial linear models (SLMs). One model was initially developed for all foraminiferal data with all environmental variables available as potential explanatory variables. The size fraction was included as a covariate as there were significant differences in foraminiferal standing crop with the different sized sieves used in the analyses (see Text S1 in Supplement 1). As foraminiferal composition is known to vary considerably between the shelf, slope and deeper waters, separate models were developed for shelf $(0-200 \mathrm{~m}$ depth), slope (200$2000 \mathrm{~m}$ ) and abyssal (2000-6000 m) observations to determine any additional patterns. Following preliminary data exploration, a $\log _{10}$ transformation of the response variables was selected to homogenise variances and normalise data. GLMs resulted in model residuals that were spatially non-independent, and therefore, SLMs were used for final inference.

Spatial analysis was performed using error-spatial autoregressive models (Dormann et al. 2007), which use maximum-likelihood spatial autoregression. Neighbourhood thresholds between 10 and $10000 \mathrm{~km}$ were tested at $10 \mathrm{~km}$ intervals and the optimal neighbourhood size for each model was selected by minimising the Akaike's information criterion (AIC) for the spatial null model (the model only retaining a spatial autocorrelation term). Backward stepwise elimination of insignificant variables was then used to determine the minimum adequate model. This approach was effective in the separate analysis of shelf, slope and abyssal data. However, in the case of the full dataset (all depths), no significant solution was found by backward stepwise elimination. Forward selection was used, which revealed similarly significant models for several single-variable and 2variable models. The importance of individual predictors was assessed through $t$-tests (GLM) and $z$ tests (SLM). The models were tested further by separately including quadratic terms and interactions between terms. These additional terms did not significantly decrease the deviance of the models compared with the simple models so were not explored further. The significance of environmental variables in describing foraminiferal standing crop was determined by examining the $p$-values from the statistical models. The regression coefficients were used to determine the magnitude and the direction of the relationships. Partial residual plots were used to show the relationship between a given independent variable and the response variable, while taking into account the influence of other independent variables also in the model. Statistical analysis was carried out using the $\mathrm{R}$ programming environment and spatial model analyses were carried out using $\mathrm{R}$ package 'spdep' (Bivand et al. 2008). 


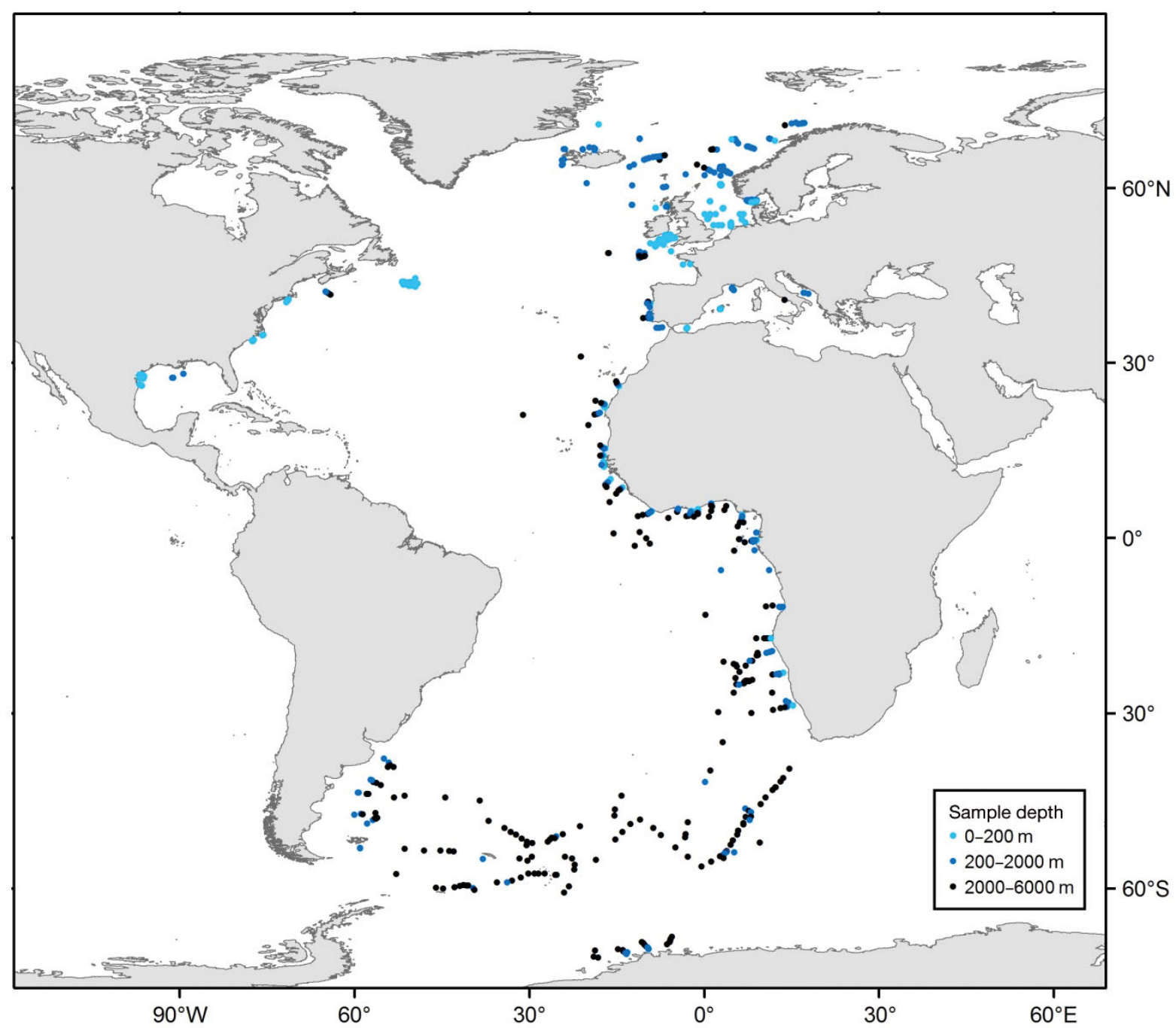

Fig. 1. Location of benthic foraminifera records used in this analysis. Symbol colour indicates the depth of the samples. No map projection used

\section{RESULTS}

\section{Patterns of standing crop of benthic foraminifera}

All associated environmental data could be found for a total of 967 quantitative foraminiferal standing crop samples from the original dataset $(\mathrm{n}=1483)$. These 967 samples ('the full dataset') are used for all analyses and provide a reasonably good spatial coverage of the Atlantic, although gaps occur in the central basins and tropical western Atlantic (Fig. 1). The global median (62 individuals [ind.] $10 \mathrm{~cm}^{-3}$ ), mean (183.4 ind. $10 \mathrm{~cm}^{-3}$ ), standard deviation (375.2 ind. $\left.10 \mathrm{~cm}^{-3}\right)$, geometric mean (68.2 ind. $10 \mathrm{~cm}^{-3}$ ) and geometric standard deviation (4.1 ind. $10 \mathrm{~cm}^{-3}$ ) of total living benthic foraminifera from 1952 to 2013 shows that they are a generally abundant but vari- able inhabitant of most marine sediments (Table 1). The maximum benthic foraminiferal standing crop is found in the Antarctic in the austral summer (4714 ind. $10 \mathrm{~cm}^{-3}$ at $314 \mathrm{~m}$ depth on the Larsen

Table 1. Summary statistics describing standing crop (numbers per $10 \mathrm{~cm}^{-3}$ ) of benthic foraminifera in the Atlantic. $\mathrm{n}$ : number of records used in analysis

\begin{tabular}{|c|c|c|c|c|c|c|}
\hline Depth (m) & $\mathrm{n}$ & $\begin{array}{l}\text { Med- } \\
\text { ian }\end{array}$ & Mean & $\mathrm{SD}$ & $\begin{array}{l}\text { Geo- } \\
\text { metric } \\
\text { mean }\end{array}$ & $\begin{array}{l}\text { Geo- } \\
\text { metric } \\
\text { SD }\end{array}$ \\
\hline All depths & 967 & 62 & 183.4 & 375.2 & 68.2 & 4.1 \\
\hline $0-200$ & 416 & 75 & 237.4 & 421.2 & 85.2 & 4.3 \\
\hline $200-2000$ & 320 & 70.2 & 199.3 & 422.2 & 69.4 & 4.8 \\
\hline$>2000$ & 231 & 44 & 64.2 & 62.3 & 44.7 & 2.4 \\
\hline
\end{tabular}


Shelf) and standing crops above 4000 ind. $10 \mathrm{~cm}^{-3}$ are found in the Rockall Trough (Feni Drift; 1980 m depth) and the Grand Banks (70 m depth), both in summer. Low benthic foraminiferal standing crops of $<1$ ind. $10 \mathrm{~cm}^{-3}$ occur in a range of locations including the North Sea, Norwegian Sea, off Iceland and in the Gulf of Mexico at a range of depths (21-2800 m).

Our analysis confirms that benthic foraminifera are present across production gradients from eutrophic coastal areas to oligotrophic areas of the oceans, across temperature gradients from polar to tropical regions and from fully oxic to suboxic conditions (Table 2). Foraminifera occur substantially deeper than the lysocline (lowest $-23.4 \mu \mathrm{mol} \mathrm{\textrm {kg } ^ { - 1 }}$ $\Delta \mathrm{CO}_{3}{ }^{2-}$ ). They are an abundant component of the benthos at shelf, slope and abyssal depths (Table 1).

\section{Environmental drivers of standing crop of benthic foraminifera}

In the full dataset, significant rela-

tionships exist between foraminiferal standing crop and a number of single variables, including temperature, DO, food supply and some nutrients (silicate and nitrate) once spatial autocorrelation is accounted for (Fig. 2, Table S3 in Supplement 1). The model can be improved by including 2 variables; the best models include either food supply and DO or temperature and DO (Table 3). The relatively strong positive correlation between food supply and temperature in the full dataset (Spearman rank correlation $\rho=0.64, p<$ 0.001; Fig. S1 in Supplement 1) means that there is little difference in the performance of models using these variables. It also means that if both temperature and POC flux are included as variables in a model only one is significant. When split into depth zones and once spatial autocorrelation has been accounted for, significant relationships with standing crop of benthic foraminifera exist with different environmental variables within each depth zone (Table 4).

Food supply is a significant explanatory variable for the standing crop of benthic foraminifera in the full dataset and at all depths (Tables $3 \& 4$ ). The full dataset shows an increase in foraminiferal standing crop with increasing food supply (Fig. 3). On the shelf, benthic foraminiferal standing crop slightly decreases with increasing food supply, a trend that is reversed in the deeper waters of the continental slope and abyss (Fig. 4A,C,E).

Benthic foraminifera occur in a broad range of seabed DO concentrations from 0.7 to $7.7 \mathrm{ml} \mathrm{O}_{2} \mathrm{l}^{-1}$ and a significant negative linear trend is observed in the full dataset. When divided into depth zones, a significant trend is only observed in the slope foraminifera (Figs. $2 \& 4$ ). The partial residual plots show that these relationships, once the other environmental variables have been held constant, are negative for DO (Figs. 3 \& 4D).

Benthic foraminifera are present across the full spectrum of Atlantic seabed temperatures between -1.7 and $23.8^{\circ} \mathrm{C}$. Temperature explains a similar amount of the variation in foraminiferal standing crop to food supply in the full dataset and has a significant negative linear relationship (Table 3). However, temperature is not significant in explaining the standing crop of foraminifera in waters shallower than $2000 \mathrm{~m}$, when separate analyses are carried out 

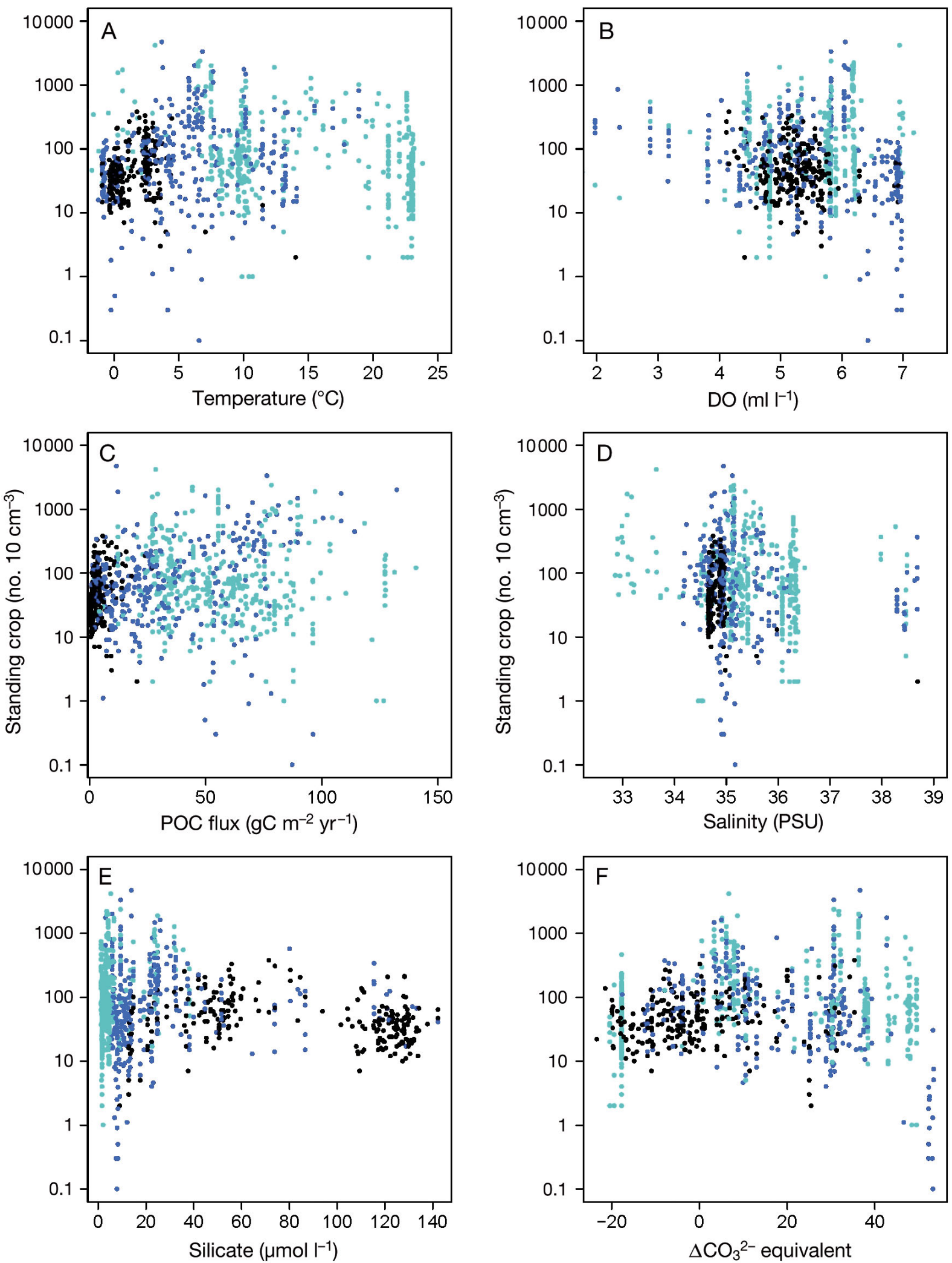

Fig. 2. Relationships between standing crop of benthic foraminifera and (A) seabed temperature, (B) dissolved oxygen (DO), (C) particulate organic carbon (POC) flux, (D) salinity, (E) silicate and (F) bottom water saturation state for $\mathrm{CaCO}_{3}$. Note log (base 10) scale on $y$-axes. Depth band indicated by colour: cyan $=0-200 \mathrm{~m}$; blue $=200-2000 \mathrm{~m}$; black $=2000-6000 \mathrm{~m}$ 
Table 3. Generalized linear model (GLM) and spatial linear model (SLM) results for 2-variable minimal adequate regression models for foraminiferal standing crop using Atlantic data. AIC: Akaike's information criterion. Moran's I is calculated on the model residuals. The number of observations in the analysis is 967 . Note that despite the spatial autocorrelation in the GLM, there is general agreement between the GLM and SLM. Size fraction is included as a covariate and is significant ( $p<0.05$ ) in all cases (except SLM Model 1: $\mathrm{p}=0.06$ ). The 2 'best' models (based on SLM AIC) are presented here, although other 2-variable models are significant

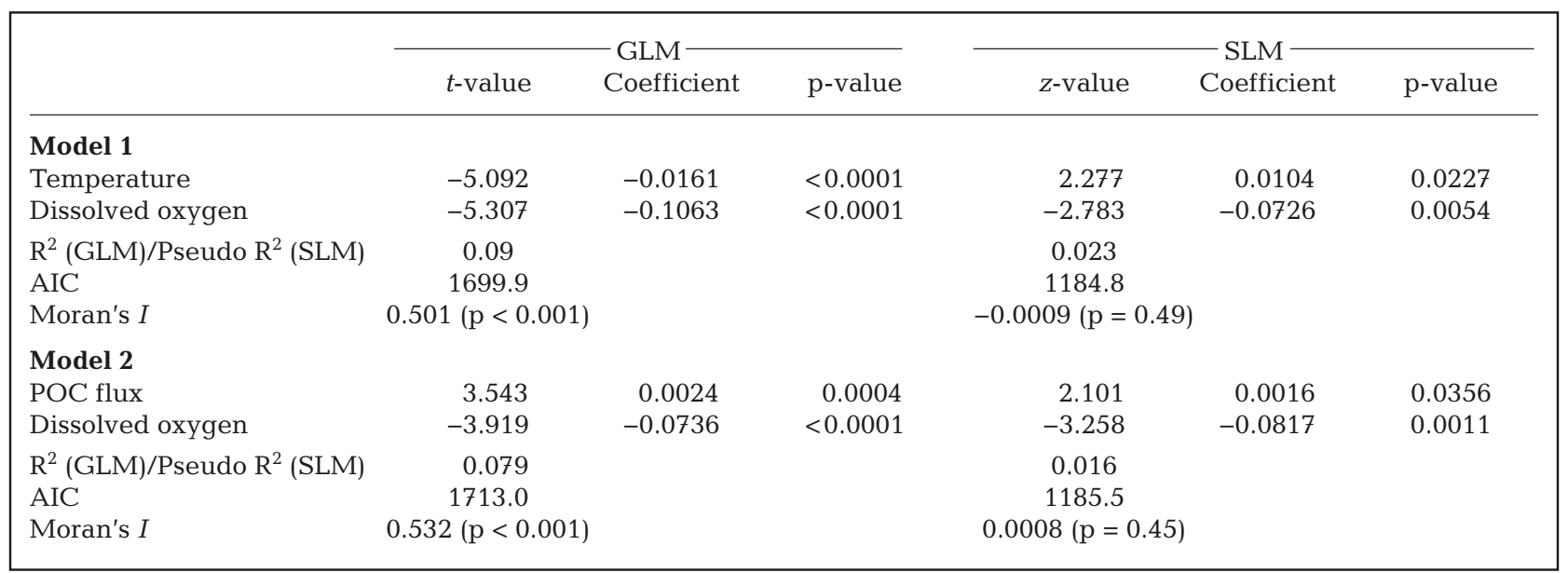

in each depth band. In the abyssal samples, standing crops are higher in areas with higher seabed temperatures. The 3 abyssal records with temperatures $>5^{\circ} \mathrm{C}$ occur in the Mediterranean $(\mathrm{n}=1)$ and Mediterranean outflow water $(\mathrm{n}=2)$ (Fig. 4F). These 3 abyssal records are also the only observations with salinities above 35.5 PSU.

This analysis focuses on foraminifera in fully saline marine waters (salinity range 32.9 to $38.7 \mathrm{PSU}$ ). In the full dataset, there are no significant relationships found between foraminiferal standing crop and salinity. When divided into depth zones, in the shallower sites $<2000 \mathrm{~m}$ there is no relationship between salin- ity and standing crop. There is a significant relationship with salinity and standing crop in waters $>2000 \mathrm{~m}$, where standing stocks are lower in areas of increased salinity (Fig. 4G). The high salinity data at all depths are all in the Mediterranean Sea and Mediterranean outflow water.

Benthic foraminifera are found at seabed silicate concentrations of 1.3 to $142.2 \mu \mathrm{mol} \mathrm{l}^{-1}$. There is a significant positive relationship between foraminiferal standing crop and silicate as a single variable in the full dataset and in shelf samples (Fig. 4B), but not on those samples taken from the slope. Silicate concentration in the full dataset and in the abyss displays a

Table 4. Generalized linear model (GLM) and spatial linear model (SLM) results for minimal adequate models for 3 depth bands in the Atlantic. Numbers indicate $t$-values (GLM) or $z$-values (SLM). Asterisks indicate significance of individual predictors: ${ }^{*} \mathrm{p}<0.05 ;{ }^{* *} \mathrm{p}<0.01$; ${ }^{* * *} \mathrm{p}<0.001$. ns: not significant. Regression coefficients are presented in parentheses. AIC: Akaike's information criterion. Moran's $I$ is calculated on the model residuals. The numbers of observations in the analysis are 416 (shelf), 320 (slope) and 231 (abyss). Note that despite the spatial autocorrelation in the GLM, there is general agreement between the GLM and SLM. The size fraction is not included as a covariate in any model as it is not a significant $(p>0.15)$ predictor of foraminiferal standing crop once the variation resulting from environmental factors has been taken into account

\begin{tabular}{|c|c|c|c|c|c|c|}
\hline & \multicolumn{2}{|c|}{ Shelf } & \multicolumn{2}{|c|}{ Slope } & \multicolumn{2}{|c|}{-Abyss- } \\
\hline & GLM & SLM & GLM & SLM & GLM & SLM \\
\hline POC flux & $-3.19(-0.004)^{* *}$ & $-2.21(-0.003)^{*}$ & $6.53(0.009)^{* * *}$ & $3.25(0.004)^{* *}$ & $2.62(0.016)^{* *}$ & $2.21(0.011)^{*}$ \\
\hline Dissolved oxygen & $\mathrm{ns}$ & ns & $-2.86(-0.089)^{* *}$ & $-2.45(-0.078)^{*}$ & $-2.76(-0.110)^{* *}$ & ns \\
\hline Temperature & $-5.65(-0.023)^{* * *}$ & ns & ns & ns & ns & $2.21(0.027)^{* * *}$ \\
\hline Salinity & $\mathrm{ns}$ & $\mathrm{ns}$ & $\mathrm{ns}$ & $\mathrm{ns}$ & $-5.75(-0.512)^{* * *}$ & $-5.91(-0.698)^{* * *}$ \\
\hline Silicate & $8.41(0.029)^{* * *}$ & $2.13(0.015)^{*}$ & $\mathrm{~ns}$ & $\mathrm{~ns}$ & $-3.54(-0.003)^{* * *}$ & $\mathrm{~ns}$ \\
\hline$\Delta \mathrm{CO}_{3}{ }^{2-}$ & ns & ns & $-5.38(-0.014)^{* * *}$ & ns & ns & ns \\
\hline $\mathrm{R}^{2}$ (GLM)/Pseudo $\mathrm{R}^{2}$ (SLM & 0.219 & 0.010 & 0.253 & 0.035 & 0.181 & 0.141 \\
\hline AIC & 709.32 & 557.78 & 541.00 & 428.33 & 162.03 & 79.47 \\
\hline Moran's $I$ & $0.383^{* * *}$ & $-0.011 \mathrm{~ns}$ & $0.417^{* * *}$ & $0.003 \mathrm{~ns}$ & $0.433^{* * *}$ & $-0.056 \mathrm{~ns}$ \\
\hline
\end{tabular}



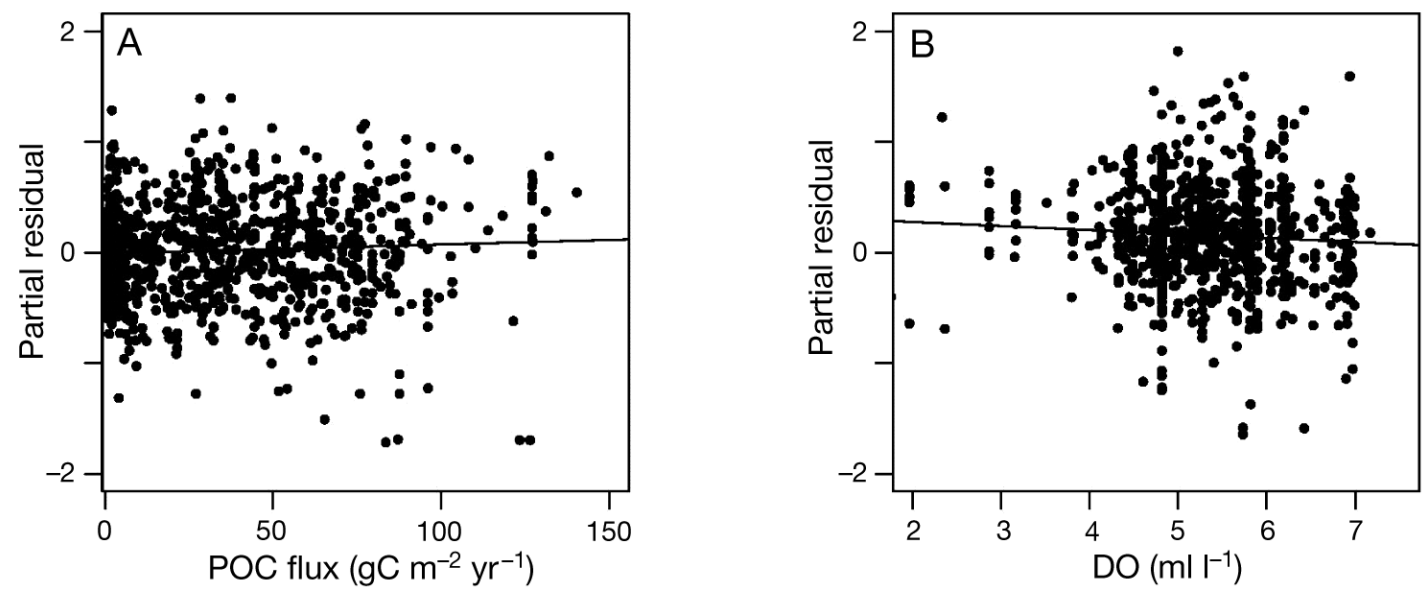

Fig. 3. Partial residual plots for the predictors of the minimum adequate spatial linear model of standing crop of benthic foraminifera and environmental variables for the Atlantic (all depths). Plots show the individual significant effects of (A) particulate organic carbon (POC) flux to the seafloor (Lutz et al. 2007) and (B) dissolved oxygen (DO). Partial residual plots are provided to visualize the independent contributions of each environmental variable. A partial residual plot is a plot of $r_{i}+b_{k} \times i_{k}$ vs. $x_{i k}$, where $r_{i}$ is the ordinary residual for the $i$ th observation, $x_{i k}$ is the $i$ th observation of the $k$ th predictor and $b_{k}$ is the regression coefficient estimate for the $k$ th predictor. Regression lines indicate partial fits

clear correlation with POC flux (Spearman rank correlation: full data: $\rho=-0.63, p<0.001$; abyss: $\rho=$ $-0.76, \mathrm{p}<0.001)$. As a result, the relationship between silicate and abyssal foraminiferal standing crop is uncertain. A suitable minimum adequate model can be constructed for foraminiferal standing crop in abyssal areas including silicate concentration instead of POC flux (AIC $=77.65, \mathrm{R}^{2}=0.154$ : similar quality to that presented in Table 4). Including both silicate concentration and POC flux does not increase explanatory power. As a result, the possibility exists that silicate is important in explaining abyssal foraminiferal standing crop. Silicate concentrations are significantly different between all depth zones (ANOVA $F=623.6, \mathrm{df}=2,964, \mathrm{p}<0.0001)$, increasing with increasing depth.

There is no significant relationship between standing crop of benthic foraminifera and bottom water saturation state for $\mathrm{CaCO}_{3}$ in the full dataset or any of the depth zones.

\section{DISCUSSION}

This study represents the first ocean-scale assessment of benthic foraminiferal standing crop. It also differs from all previous studies because it uses a single data source for POC flux to the seafloor (Lutz et al. 2007) based on global surface productivity data (Garcia et al. 2014b). Previous studies have been regional and have used a variety of estimates of surface productivity and different formulae to calculate
POC flux (see Jorissen et al. 2007), hindering comparison. Also, previous studies have used a variety of single size fractions to determine standing crop, from $>63$ to $>150 \mu \mathrm{m}$. In this synthesis, all size fractions of foraminifera were combined.

\section{Limitations of the foraminiferal data}

The standing crop measured in a single sample is the sum of individuals of all the species present in a unit area or volume of seafloor sediment. It is now known that benthic foraminifera show small-scale patchiness in their distribution so, ideally, replicate samples should be taken to assess these patterns (Gooday 2003). These patches vary though time and have been termed 'pulsating patches' (Buzas et al. 2015). In addition, there is seasonal variation in input of POC to the seafloor even in the deep sea (Gooday 1988, 2003) and this seasonality affects the size of the standing crop (see review by Jorissen et al. 2007). Also there is loss of individuals through predation and disturbance mainly by macrofauna (Buzas et al. 1989). Data on the deep sea and continental shelves were obtained from as many literature studies as possible from the period 1952-2013 (Murray 2015). Therefore, the dataset is not an instantaneous snapshot, but a synopsis of data gathered over 6 decades and collected at different seasons of the year. The geographic coverage is dictated by the availability of studies; there are large areas that have not yet been sampled especially in the deeper parts of the deep sea away from continental margins. 

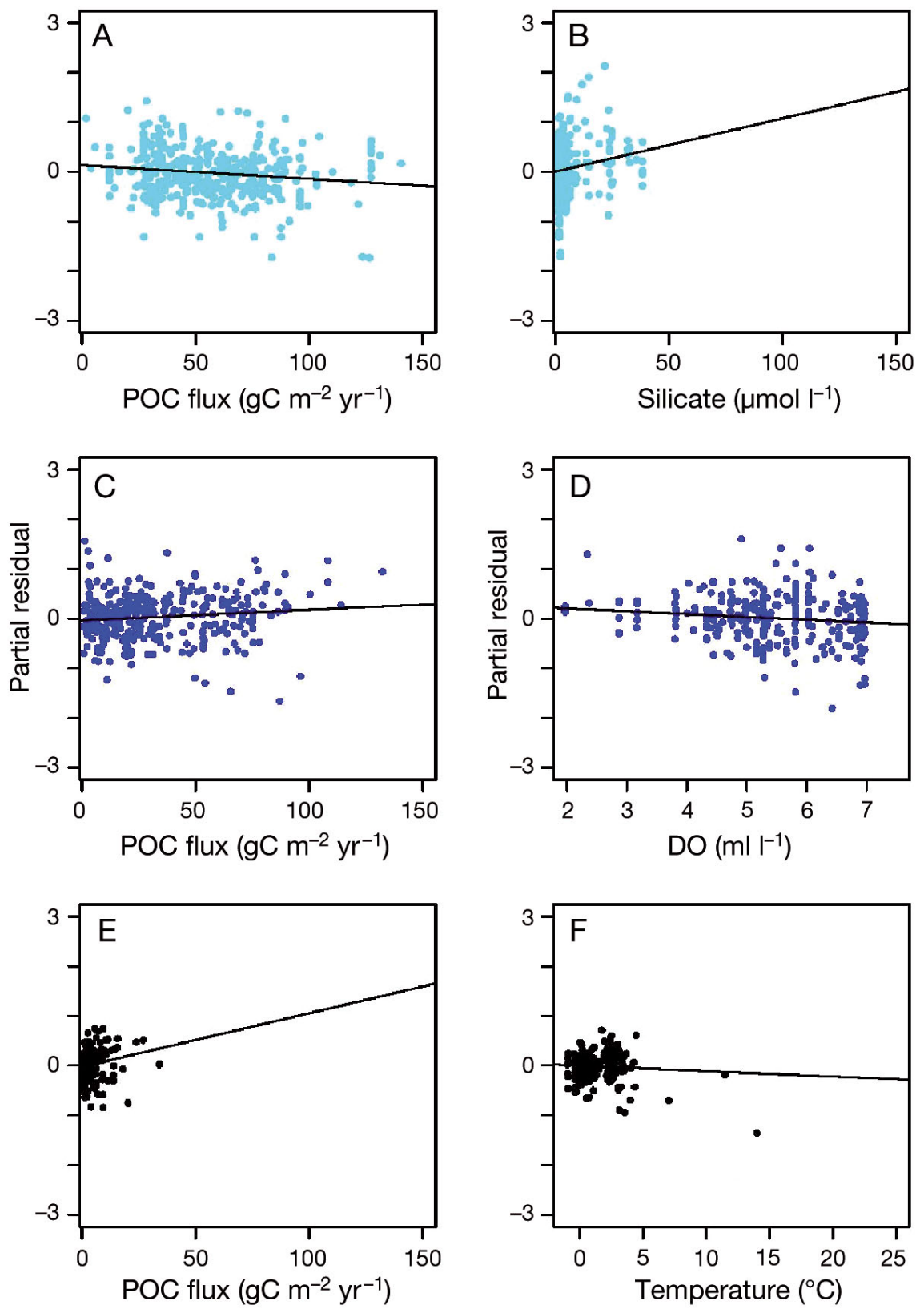

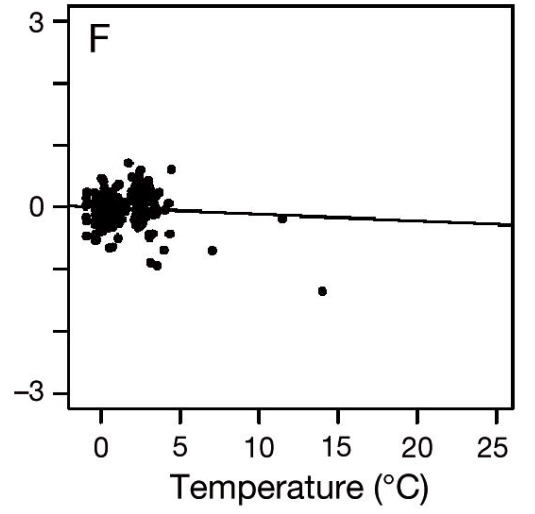

Fig. 4. Partial residual plots for the predictors of the minimum adequate spatial linear model standing crop of benthic foraminifera and environmental variables for 3 depth bands in the Atlantic: $(\mathrm{A}, \mathrm{B}) \mathrm{0}-200 \mathrm{~m}$ (cyan); (C,D) 200-2000 m (blue); (E-G) >2000 m (black). Plots show the individual significant effects of $(\mathrm{A}, \mathrm{C}, \mathrm{E})$ particulate organic carbon (POC) flux to the seafloor (Lutz et al. 2007), (B) silicate, (D) dissolved oxygen (DO), $(\mathrm{F})$ temperature and (G) salinity. Partial residual plots are provided to visualize the independent contributions of each environmental variable. See Fig. 3 for description of a partial residual plot. Regression lines indicate partial fits
The Rose Bengal staining method for distinguishing individuals considered to be alive at the time of collection was introduced in 1952 and has been widely used ever since. However, Rose Bengal is not a vital stain and therefore some workers have suggested that recently dead individuals may also become stained and thus give an overestimate of the numbers alive (see Murray \& Bowser 2000 and Bernhard et al. 2006 for discussion).

Notwithstanding these limitations, we believe that the dataset used in this ocean-wide study is adequate to determine the major controlling factors governing the size of the standing crop.

\section{Limitations of the approach}

Data collected using multiple methods were combined in this study to provide a broad-scale overview of potential environmental drivers of foraminiferal standing crop. This approach is at present the only way to address important regional questions, but comes with a number of limitations (further discussion in Text S1 in Supplement 1). First, the combination of data collected with different size fractions introduces a covariate, which will increase error in estimates. Foraminiferal standing crop was, as would be expected (McClain et al. 2012), significantly 
higher in samples taken with smaller sieves and there were some spatial patterns in the size fraction analysed (Fig. S2 in Supplement 1). Second, there was inevitable correlation between environmental variables (Fig. S1 in Supplement 1), which limits our ability to determine which of a correlated set of environmental variables the key driver is. It should also be stressed that although data were collected throughout the year and over 6 decades (Murray 2015), there were insufficient samples to resolve seasonal or interannual variability.

\section{Role of POC in determining foraminiferal standing crop}

Food supply appears the most likely of the correlated environmental variables, such as temperature and silicate, to be the primary driver for foraminiferal standing crops. This assumption is supported by our analyses, for example, by the consistent relationships between food supply and standing crop in the full data and across the separate depth zones, and a large body of literature (Murray 2015). Our results show a general pattern of increasing foraminiferal standing crop with increased food supply, but more detailed assessment shows that there is a different response to POC between shelf and deeper areas in the Atlantic. In general, on the slope and in the abyss, the positive relationship between standing crop and POC generally reported in localised studies of the deep sea (e.g. Schmiedl et al. 1997) is also found here at the scale of an ocean (Fig. 4C,E). Increases in standing crop with food supply are expected and supported by ecological theory (e.g. McClain et al. 2012). Surprisingly, on the shelf there is a significant negative relationship between POC flux and standing crop (Fig. 4A). This relationship deserves further experimental assessment. However, the explanation for this negative relationship could be a function of some other cocorrelating factor. For example, increases in POC flux may lead to increases in predation pressure, causing localised losses in standing crop (Buzas et al. 1989). Areas with high POC flux on the shelf could also be associated with other environmental controls. Studies of shelf sea foraminiferal distributions show sediment lithology and tidal and/or wave energy to be important controls on species abundance. Areas of high energy with sandy substrates have much lower standing crops than low energy muddy substrates (Murray 2006, p. 158). In shallow areas, the satellite-derived estimates of POC flux to the seafloor are likely less accurate-lateral advection, resus- pension and preferential accumulation in areas of fine-grained sediment may all influence spatial patterns. Perhaps the most likely explanation for unexpected patterns is that resource quality cannot be determined from the satellite-derived measure of POC flux used in this analysis. Refractory material, which is more common on the shelf, is a poor food resource compared with labile organic matter (Licari et al. 2003, Fontanier et al. 2008). In general, there is a large spread of standing crop for a given value of POC flux at all depths, which could also be explained by variation resulting from these factors.

\section{Abiotic factors}

There is a negative correlation between DO and standing crop in the full dataset and on the slope. It is known that when oxygen availability is restricted it adversely affects the benthic foraminifera. However, above a threshold of $\sim 1.0 \mathrm{ml} \mathrm{O}_{2} \mathrm{l}^{-1}=45 \mu \mathrm{M}$, oxygen is no longer a limiting factor for foraminifera (Gooday 2003) so the majority of open-sea assemblages are not limited by oxygen. An oxygen minimum zone is intermittently developed along the African slope, in the vicinity of Angola and Namibia. DO values $<1.0 \mathrm{ml} \mathrm{O}_{2} \mathrm{l}^{-1}$ only occur at 3 stations in our data from 193, 531 and $1965 \mathrm{~m}$ in an oxygen minimum zone off the Cunene River at $17^{\circ} \mathrm{S}$ in the SE Atlantic (original data in Schmiedl et al. 1997). It is possible that loweroxygen areas had lower numbers of active megafauna that may compete with foraminifera for labile phytodetritus. Reduced POC flux attenuation in the oxygen minimum zone, and a resultant higher seabed POC flux than model predictions, may occur as a consequence of reduced mesopelagic zooplankton feeding and microbial degradation activities (e.g. Keil et al. 2016).

Dissolved silicate is a significant factor on the shelf and abyss, but not between 200 and $2000 \mathrm{~m}$. As silica is not utilised in test construction by benthic foraminifera, its correlation with standing crop was unexpected. One possible explanation is that it is an indication of the type of organic detritus, e.g. diatoms or silicoflagellates. As shown in 'Results', either silicate or POC could be the drivers in the abyss.

Bottom water temperature has long been known to be a control on species distributions, especially in shelf and marginal marine environments. It is difficult to separate the effects of temperature from those of food supply. Our data indicate that temperature may have a particular influence on the amount of foraminiferal standing crop in the deep sea, which 
has not previously been recognised in the foraminiferal literature. The body of ecological theory (e.g. the metabolic theory of ecology; Brown et al. 2004) and observations for other taxa would support a temperature relationship, relating temperature increases to elevated metabolic rate, biomass and population sizes (McClain et al. 2012). However, it should be recognised that the range of temperatures exhibited in the deep sea is relatively small compared with other environments.

It is likely that the trends observed here associated with temperature and salinity were driven by outlying low foraminiferal standing crops associated with the oligotrophic, high-temperature and high-salinity Mediterranean and Mediterranean outflow water on the Portuguese slope. Low foraminiferal standing crops in Mediterranean outflow has been observed before and associated with a decrease in labile POC at the sediment surface (Fontanier et al. 2008).

The saturation state for $\mathrm{CaCO}_{3}$ may be more important as a factor influencing taphonomy (dissolution of calcareous tests) rather than as a control on living forms. A wide variety of benthic calcifiers live in waters undersaturated with $\mathrm{CaCO}_{3}$, using a range of sophisticated mechanisms for constructing and maintaining their $\mathrm{CaCO}_{3}$ structures (Lebrato et al. 2016).

Although there were no data on bottom currents for each sampling site, such currents are considered to be responsible for locally controlling standing crops. In areas of high current speed (up to $50 \mathrm{~cm} \mathrm{~s}^{-1}$ ), the seabed is winnowed and standing crops are low (Schönfeld 2002). In Walvis Bay, bottom nepheloid layers flowing from shelf down slope transport organic detritus to greater depths and lead to higher standing crops than at shallower depths (54 and 189 ind. $10 \mathrm{~cm}^{-3}$ at 892 and $1957 \mathrm{~m}$ respectively; Fontanier et al. 2013).

In summary, at the scale of an ocean, POC flux is important in controlling foraminiferal standing crop across all depths, as previously determined in regional studies. Locally, on the continental slope, DO concentration is important and in deeper waters temperature and salinity have a significant effect on foraminiferal standing crops.

\section{Relevance to palaeoceanographic studies}

Benthic foraminiferal tests are the main benthic meiofauna in fossil deep-sea sediments and macrofaunal remains are relatively rare. Therefore, benthic foraminifera offer the best prospect for interpreting past deep-sea environments (Jorissen et al. 2007).
Two approaches are taken: study of individual species and study of assemblages of tests. Only the latter is relevant to this study. The correlation between standing crop and POC flux forms the basis for the establishment of a palaeoceanographic proxy for productivity, namely the benthic foraminiferal accumulation rate (BFAR). The merits and problems associated with BFAR have been reviewed in detail by Gooday (2003) and Jorissen et al. (2007) and will not be repeated here. However, there is a fundamental difference between BFAR, which is a rate process and includes a time element (usually of thousands of years), and standing crop, which is a stock at a specific time. In view of the wide range of standing crops for a given value of POC flux observed here, together with the range of other factors that influence standing crop, it is likely that the BFAR should be viewed as a measure of relative rather than absolute productivity change.

\section{CONCLUSIONS}

The aim of this study was to test whether relationships between standing crop and environmental factors observed in regional studies were still observed at the scale of the Atlantic Ocean. Six decades of foraminiferal standing crop data analysed here strongly support the correlation between standing crop and POC flux for the ocean and indicate the importance of DO, but more detailed analysis reveals differences between the continental shelf and deeper waters $>200 \mathrm{~m}$. On the shelf, observed patterns of foraminiferal standing crop are complex. There is a decrease in standing crop with increase in POC flux and there is a positive correlation with dissolved silica, possibly indicating that siliceous organisms enhance foraminiferal standing crops or that other factors correlating with POC flux are important, e.g. lateral advection of POC. In deeper water (>200 m), the oceanic-scale data presented here confirm the observations from local studies that the primary factor controlling benthic foraminiferal standing crop is the flux of POC. Bottom waters are well-oxygenated except on localised areas of the African slope and never fall to values that affect the benthic foraminifera. Only extremes of temperature and salinity in deep water associated with the Mediterranean appear to be associated with lower standing crop values. There is no significant relationship between standing crop and the saturation state for $\mathrm{CaCO}_{3}$ at any depth. Although it might be expected that the size fraction examined would influence the magni- 
tude of standing crop, it appears that variation between samples as a result of environmental variation is orders of magnitude larger than the variation cause by changes in size fraction (Text S1 in Supplement 1).

This paper has implications for palaeoceanography. Our results highlight the correlations between standing crop and productivity, supporting the use of benthic foraminiferal accumulation rate (BFAR) as a palaeoceanographic proxy for productivity, at least in deeper waters. However, our results suggest wide variability in response as well as additional factors that influence standing crop, at least for short-term measurements of standing crop, which have not been integrated over time. The large dataset assembled here is important more generally for deep-sea ecologists. It can feed into other deep-sea macroecological studies, as well as provide baseline data for assessing the impacts of global change.

Acknowledgements. We thank the many authors who over the years have supplied spreadsheets of foraminiferal data, without which this study would have been impossible. D.O.B.J. was supported for this work by the UK Natural Environment Research Council through National Capability funding to the National Oceanography Centre.

\section{LITERATURE CITED}

Alve E, Lepland A, Magnusson J, Backer-Owe K (2009) Monitoring strategies for re-establishment of ecological reference conditions: possibilities and limitations. Mar Pollut Bull 59:297-310

Alve E, Korsun S, Schönfeld J, Dijkstra N and others (2016) Foram-AMBI: a sensitivity index based on benthic foraminiferal faunas from the North-East Atlantic and Arctic fjords, continental shelves and slopes. Mar Micropaleontol 122:1-12

Archer DE (1996a) A data-driven model of the global calcite lysocline. Global Biogeochem Cycles 10:511-526

*Archer DE (1996b) An atlas of the distribution of calcium carbonate in sediments of the deep sea. Global Biogeochem Cycles 10:159-174

Bernhard JM, Ostermann D, Williams DS, Blanks JK (2006) Comparison of two methods to identify live benthic foraminifera: a test between Rose Bengal and CellTracker Green with implications for stable isotope paleoreconstructions. Paleoceanography 21:PA4210

Bivand RS, Pebesma E, Gómez-Rubio V (2008) Applied spatial data analysis with R. Springer, New York, NY

Brown JH, Gillooly JF, Allen AP, Savage VM, West GB (2004) Towards a metabolic theory of ecology. Ecology 85:1771-1789

Buzas MA, Collins LS, Richardson SL, Severin KP (1989) Experiments on predation, substrate preference, and colonization of benthic foraminifera at the shelfbreak off the Ft. Pierce Inlet, Florida. J Foraminiferal Res 19:146-152

Buzas MA, Hayek LA, Jett JA, Read DA (2015) Pulsating patches. History and analyses of spatial, seasonal, and yearly distribution of living benthic foraminifera. Smith- sonian Contributions to Paleobiology 97, Smithsonian Institution Scholarly Press, Washington, DC

* Dormann CF, McPherson JM, Araújo MB, Bivand RS and others (2007) Methods to account for spatial autocorrelation in the analysis of species distributional data: a review. Ecography 30:609-628

Fontanier C, Jorissen FJ, Lansard B, Mouret A and others (2008) Live foraminifera from the open slope between Grand Rhône and Petit Rhône canyons (Gulf of Lions, NW Mediterranean). Deep Sea Res I 55:1532-1553

Fontanier C, Metzger E, Waelbroeck MJ, LeFloch N and others (2013) Live (stained) benthic foraminifera off Walvis Bay, Namibia: a deep-sea ecosystem under the influence of bottom nepheloid layers. J Foraminiferal Res 43:55-71

Garcia HE, Locarnini RA, Boyer TP, Antonov JI and others (2014a) In: Levitus S, Mishonov A (eds) World ocean atlas 2013, Vol 3. Dissolved oxygen, apparent oxygen utilization, and oxygen saturation. NOAA Atlas NESDIS 75, NOAA, Silver Spring, MD, p 1-27

Garcia HE, Locarnini RA, Boyer TP, Antonov JI and others (2014b) In: Levitus S, Mishonov A (eds) World ocean atlas 2013, Vol 4. Dissolved inorganic nutrients (phosphate, nitrate, silicate). NOAA Atlas NESDIS 76, NOAA, Silver Spring, MD, p 1-25

Gooday AJ (1988) A response by benthic foraminifera to the deposition of phytodetritus in the deep sea. Nature 332: 70-73

Gooday AJ (2003) Benthic foraminifera (Protista) as tools in deep-water palaeoceanography: environmental influences on faunal characteristics. Adv Mar Biol 46:1-90

*Gooday AJ, Jorissen F (2012) Benthic foraminiferal biogeography: controls on global distribution patterns in deep-water settings. Annu Rev Mar Sci 4:237-262

Gooday AJ, Levin L, Linke P, Heeger T (1992) The role of benthic foraminifera in deep-sea food webs and carbon cycles. In: Rowe GT, Pariente V (eds) Deep-sea food chains and the global cycle. Kluwer Academic Publishers, Dordrecht, p 63-91

Jones RW (2009) Stratigraphy, palaeoenvironmental interpretation and uplift history of Barbados based on foraminiferal and other palaeontological evidence. J Micropalaeontol 28:37-44

Jones DOB, Yool A, Wei CL, Henson SA, Ruhl HA, Watson RA, Gehlen M (2014) Global reductions in seafloor biomass in response to climate change. Glob Change Biol 20:1861-1872

Jorissen FJ, Fontanier C, Thomas E (2007) Paleoceanographic proxies based on deep-sea benthic formaniniferal assemblage characteristics. In: Hillaire-Marcel E, de Vernal C (eds) Proxies in Late Cenozoic paleoceanography: Pt 2: biological tracers and biomarkers. Developments in Marine Geology 1, Elsevier, Amsterdam, p 263-326

Katz M, Cranmer BS, Framzese A, Hönisch B, Miller KG, Rosenthal Y, Wright JD (2010) Traditional and emerging geochemical proxies in foraminifera. J Foraminiferal Res 40:165-192

Keil RG, Neibauer J, Biladeau C, van der Elst K, Devol AH (2016) A multiproxy approach to understanding the "enhanced" flux of organic matter through the oxygendeficient waters of the Arabian Sea. Biogeosciences 13: 2077-2092

Lebrato M, Andersson AJ, Ries JB, Aronson RB and others (2016) Benthic marine calcifiers coexist with $\mathrm{CaCO}_{3}$ undersaturated seawater worldwide. Global Biogeo- 
chem Cycles 30:1038-1053

Licari LN, Schumacher S, Wenzhöfer F, Zabel M, Mackensen A (2003) Communities and microhabitats of living benthic foraminifera from the tropical east Atlantic: impact of different productivity regimes. J Foraminiferal Res 33:10-31

Locarnini RA, Mishonov AV, Antonov JI, Boyer TP and others (2013) In: Levitus S, Mishonov A (eds) World ocean atlas 2013, Vol 1. Temperature. NOAA Atlas NESDIS 73, NOAA, Silver Spring, MD, p 1-40

Lutz MJ, Caldeira K, Dunbar RB, Behrenfeld MJ (2007) Seasonal rhythms of net primary production and particulate organic carbon flux to depth describe the efficiency of biological pump in the global ocean. J Geophys Res 112: C10011

McClain CR, Allen AP, Tittensor DP, Rex MA (2012) Energetics of life on the deep seafloor. Proc Natl Acad Sci USA 109:15366-15371

Murray JW (2006) Ecology and applications of benthic foraminifera. Cambridge University Press, Cambridge

Murray JW (2015) Some trends in sampling modern living (stained) benthic foraminifera in fjord, shelf and deep sea: Atlantic Ocean and adjacent seas. J Micropalaeontol 34:101-104

Murray JW, Bowser SS (2000) Mortality, protoplasm decay rate, and reliability of staining techniques to recognize 'living' foraminifera: a review. J Foraminiferal Res 30: $66-70$

Nardelli MP, Barras C, Metzger E, Mouret A, Filipsson HL, Jorissen F, Geslin E (2014) Experimental evidence for foraminiferal calcification under anoxia. Biogeosciences

Editorial responsibility: Marsh Youngbluth,

Fort Pierce, Florida, USA

\section{1:4029-4038}

* Rex MA, Etter RJ, Morris JS, Crouse J and others (2006) Global bathymetric patterns of standing stock and body size in the deep-sea benthos. Mar Ecol Prog Ser $317: 1-8$

Schmiedl G, Mackensen A, Müller PJ (1997) Recent benthic foraminifera from the eastern South Atlantic Ocean: dependence on food supply and water masses. Mar Micropaleontol 32:249-287

Schönfeld J (2002) Recent benthic foraminiferal assemblages in deep high-energy environments from the Gulf of Cadiz (Spain). Mar Micropaleontol 44:141-162

Smith CR, De Leo FC, Bernardino AF, Sweetman AK, Arbizu PM (2008) Abyssal food limitation, ecosystem structure and climate change. Trends Ecol Evol 23:518-528

* Tittensor DP, Mora C, Jetz W, Lotze HK, Ricard D, Vanden Berghe E, Worm B (2010) Global patterns and predictors of marine biodiversity across taxa. Nature 466: 1098-1101

* Van der Zwaan GJ, Duinstee IAP, Den Dulk M, Ernst S, Janninck NT, Kouwenhoven TJ (1999) Benthic foraminifers: proxies or problems?: A review of paleoecological concepts. Earth Sci Rev 46:213-236

Walton WR (1952) Techniques for recognition of living foraminifera. Contrib Cushman Found Foraminifer Res 3: 56-60

Zweng MM, Reagan JR, Antonov JI, Locarnini RA and others (2013) In: Levitus S, Mishonov A (eds) World ocean atlas 2013, Vol 2. Salinity. NOAA Atlas NESDIS 74, NOAA, Silver Spring, MD, p 1-39

Submitted: April 25, 2017; Accepted: August 10, 2017 Proofs received from author(s): October 3, 2017 